Session 2270

\title{
Richmond Area Program For Minorities In Engineering Summer Engineering Institute
}

\author{
Rosalyn S. Hobson ", Kenneth Burbank ${ }^{* *}$ \\ *Virginia Commonwealth University/** Virginia State University
}

\begin{abstract}
The Richmond Area Program for Minorities in Engineering (RAPME) is a non-profit organization whose primary goal is to influence minority middle and high school students to consider engineering as a profession. RAPME developed two programs to aid in accomplishing its goal: the Summer Engineering Institute and the RAPME Annual Scholarship. This paper provides an overview of the Summer Engineering Institute.
\end{abstract}

I. Introduction

In 1998 in the United States of America only 7.1\% of the Bachelor of Arts and Bachelor of Science degrees awarded in science and engineering were awarded to African American students, $5.8 \%$ and $0.6 \%$ of these degrees were awarded to Hispanic and to American Indian students respectively. On October 11, 1977 a group of concerned citizens from the Richmond/Petersburg metropolitan area met to discuss the lack of minority representation in the field of engineering. These citizens, from various universities, businesses and industries, met with the intent to bring to surface the reality of the extreme shortage of minorities in engineering. They wanted to help minority students gain an appreciation for science and technology and its role in society. They also hoped to motivate the students to choose careers in engineering. Finally, this group wanted to aid these students in building a strong background in mathematics and physical sciences; a background that would enable the student to enter directly into the core curriculum of any engineering school with confidence in their ability to successfully complete the program and graduate.

Consequently, from these ideas came the development of the Richmond Area Program for Minorities in Engineering (RAPME). RAPME, a non-profit organization, was officially incorporated in July 1978 with 10 sponsors. RAPME developed two recognized programs to aid in accomplishing its goals: the Summer Engineering Institute and the RAPME Annual Scholarship. In 1978 the first Summer Engineering Institute (SEI) was held on the campus of Virginia Commonwealth University (VCU). Fifty-nine students participated from four different public school systems and forty-nine successfully completed the program. 
Since then the program has expanded to include ten public school systems, over forty-five private schools and area churches, Virginia State University (VSU), J. Sargeant Reynolds Community College (JSRCC) and a total of thirteen corporate sponsors. The corporate sponsors include: ABB, AlliedSignal, Bell Atlantic, Brenco, Carpenter, Dominion Virginia Power, DuPont, Ethyl, Motorola, Philip Morris, Reynolds Metals, Stone Corporation, and VIASYSTEMS. The Summer Engineering Institute has grown from fifty-nine students participating to as many as 145 participants in 1997. In 1980, Virginia State University began hosting the SEI. In the summer of 2000 a total of ninety-four middle and high school minority students participated and successfully completed the program.

The Summer Engineering Institute has grown into a four-phase program to accommodate students at different academic levels. Participants include students from age twelve (middle school) to age seventeen (rising seniors). During the program, students were introduced to many concepts concerning engineering education. These students also witnessed the engineering profession first hand by attending lectures given by practicing engineers and by visiting various industrial facilities and engineering schools.

\section{The Summer Engineering Institute}

The SEI is a 3/6-week educational program for middle and high school minority students. The program takes place at Virginia State University, J. Sargeant Reynolds Community College and Virginia Commonwealth University. The program is divided into four different phases. Each phase addresses the needs of a specific grade and academic level. Phases I - III attend daily sessions Monday through Friday from 9:00 AM to 12:00 PM. Phase IV attends Monday through Thursday from 8:00 AM to 2:00 PM. Phases I - III are three week sessions which are held at VSU and at VCU consecutively. Phase IV is a six-week program held at JSRCC. The main focus of these phases is to reinforce a students' mathematics training and introduce them to engineering and computer concepts. The curriculum also includes weekly field trips to engineering oriented operations and universities in hopes of broadening the students' concept of engineering.

The application consists of four parts. There is a small processing fee of $\$ 15$ for Phases I - III and $\$ 50$ for Phase IV which covers administrative costs incurred in successfully running a program such as this. Everything else is provided by RAPME, including a T-shirt upon successful completion of the program. The total cost to administer the program is approximately $\$ 10,000$ annually.

PHASE I is a three-week program for rising $7^{\text {th }}-9^{\text {th }}$ grade students. Because this is the first level and targets the middle school student, there are no academic requirements. This phase introduces students to practicing engineers and familiarizes them with the profession. This is accomplished by inviting engineers to talk to students about their jobs and educational background. Students also participate in a classroom setting completing assigned tasks and engineering related projects. Projects include a truss made of toothpicks, rocket kits and dragster kits. Students also attend field trips to witness first hand engineers and the work they do. The maximum class size for this phase is 30 students. 
PHASE II is a three-week program for rising $9^{\text {th }}-11^{\text {th }}$ grade students. Completion of Algebra 1 is a mathematics prerequisite for this phase. Phase II students attend three classes daily: Mathematics Concepts, Engineering Concepts and Computer Concepts. These classes are structured so that they enhance the student's school curriculum. Phase II also attends field trips to local area businesses that deal with engineering as well as hear lectures given by engineers. The maximum class size for this phase is 15 students.

PHASE III is a three-week program for rising $10^{\text {th }}-12^{\text {th }}$ grade students. Completion of Algebra 1 and Geometry is a mathematics prerequisite for this phase. Phase III students are exposed to daily classes that enhance their school curriculum. Advanced Mathematics Concepts, Advanced Engineering Concepts/Drafting and Advanced Computer Concepts are the classes taught. Phase III students also attend field trips and lectures. The maximum class size for this phase is 15 students.

PHASE IV is a six-week, advanced academic program. Former Phase II/III students or other talented rising $12^{\text {th }}$ grade students are eligible for this phase. Students are exposed to courses that are closely related to the courses usually taken during one's freshman year of engineering school. Qualified applicants are selected on the basis of the following criteria: mathematics and science ability, the students high school academic record and the student's intent to pursue a college degree in Engineering. Students can earn (6) college credit hours in Computer Methods in Engineering and Technology, Electromechanical Engineering and Engineering Technical Mathematics. Phase IV students also attend field trips and lectures. The maximum class size for this phase is 12 students.

Applying for the Summer Engineering Institute is a very competitive process. Students must submit an application along with official high school transcripts, standardized test scores, a letter of recommendation from a school official and a 200 word (or less) essay on why they want to participate in the RAPME SEI program. The SEI Application Selection Committee, as appointed by RAPME's Board of Directors, selects the most qualified students. Students are then notified and asked for confirmation as to their attendance.

\section{The 2000 Summer Engineering Institute}

Virginia State University hosted phases I - III of the 2000 SEI for three weeks from June 26, 2000 through July 14, 2000. Virginia Commonwealth University hosted phases I - III from July 17, 2000 through August 4, 2000. J. Sargeant Reynolds hosted phase IV from June 21, 2000 through July 27, 2000. Applications were mailed to more than 100 local schools, both public and private. In addition, applications were sent to the previous year's attendees and to those who called the RAPME office. Students were chosen to participate in the program based upon their application. Applications were reviewed by the Selection Committee, a subcommittee of the RAPME Board of Directors. The selection committee identified the selected students, the wait listed students (in order) and the rejected students. Selected students were mailed acceptance letters by May 30, 2000. Late applicants were measured against known, accepted candidates, and were further reviewed by phone by one of the committee members. 
The 2000 SEI was launched with the Family Orientation Program on June 13. Mr. Levi Cary, the Virginia Department of Transportation (VDOT) Division Administrator, Equal Opportunity Division, was the featured speaker.

\begin{tabular}{|c|c|c|c|c|}
\hline \multicolumn{4}{|c|}{ 2000 SEI Student Numbers } \\
\hline \multirow{3}{*}{ VCU } & \multicolumn{2}{|c|}{ Applications } & 29 & \\
& I & 73 & 11 & \\
\cline { 2 - 5 } & II & 22 & 9 & 49 \\
\cline { 2 - 5 } & III & 12 & 19 & \\
\hline \multirow{2}{*}{ VSU } & I & 28 & 14 & 38 \\
\cline { 2 - 5 } & II & 17 & 5 & 7 \\
\cline { 2 - 5 } & III & 5 & 7 & 94 \\
\hline JSRCC & IV & 9 & & \\
\hline Total & & 167 & 9 & \\
\hline
\end{tabular}

Table 1. Summer Engineering Institute applicants and attendees.

Along with the classroom instruction that the SEI participants received, the students also participated in a number of field trips. The goal was one field trip per week for Phases I, II, and III. Phase I traveled as a group, while Phases II and III traveled together. Phase IV students were invited on the DuPont trip, but none attended.

\begin{tabular}{|c|c|c|}
\hline & \multicolumn{2}{|c|}{ 2000 SEI Field Trips } \\
\hline Phase I & VSU & VCU \\
& $\begin{array}{c}\text { VA Power, Chesterfield plant } \\
\text { VDOT Materials Lab }\end{array}$ & $\begin{array}{c}\text { VA Power, Chesterfield plant } \\
\text { VDOT Materials Lab } \\
\end{array}$ \\
\hline Phase II, & VDOT Central Office & Carpenter Company \\
Phase III & DuPont Teijin Films & VDOT Central Office \\
& & DuPont Teijin Films \\
\hline Phase IV & & DuPont Teijin Films \\
\hline
\end{tabular}

Table 2. Summer Engineering Institute field trips.

There were a number of guest speakers invited from different disciplines of engineering to talk to the students about careers in their respective fields of engineering.

\begin{tabular}{|l|l|l|}
\hline \multicolumn{3}{|c|}{ 2000 SEI Guest Speakers } \\
\hline Julius Volgyi, VDOT, Civil Engineer, bridge division & VSU & VCU \\
\hline Robert Spain, City of Richmond, NSBE, Civil Engineering & I,II,III & I \\
\hline Dr. Rosaly,III \\
\hline Ed Baine, VA Power, EE & I,II,III & I,II,III \\
\hline
\end{tabular}

Proceedings of the 2001 American Society for Engineering Education Annual Conference \& Exposition Copyright @ 2001, American Society for Engineering Education 


\begin{tabular}{|l|l|l|}
\hline Alan Meekins, VA Power & & I,II,III \\
\hline Ceasar Jackson, Physics grad student, NSBE & I & \\
\hline Dr. Tim Cameron, VCU, Mechanical Engineer, lab tour & & I,II,III \\
\hline Dr. Rob Pearson, VCU, EE, microelectronics lab & & II, III \\
\hline Ms. Naomi Weathers, Weathers Engineering, Civil Eng & & all \\
\hline
\end{tabular}

Table 3. Summer Engineering Institute guest speakers.

In the classroom there were 4 instructors, and 2 student assistants for Phases I through III. In addition, there are three instructors at JSRCC. In Phase I the students worked on three different projects over the three-week period. The current Phase I projects were bridge building, solar powered cars, and rockets. We found that the rockets were too simple and did not allow for any redesign. The solar cars were also simple, but the students could quickly build-test-rebuild and try many things. The bridge building project was successful because engineers from VDOT worked with the students on the design of the bridges. Some recommendations for changes in Phase I include adding the Lego based Mindstorms computerized robots to Phase I and removing the rocket and solar car projects. Additionally we found that the class size of 30 for Phase I was too large during project construction. A recommendation is to split the class in half, with one college student assistant per room, and one lead teacher.

In Phase II and III the students attend three classes: a computer class, a mathematics class and a engineering concepts class. The computer class was devoted to Excel and PowerPoint. Most of the students in Phases II and III know these packages. A recommendation is to move this material to Phase I. We also found having the three classes each day for Phases II and III was boring and no connection was being made between the subjects. The recommendation is to go to a project-based program, where math and computer packages are used in the engineering solution of a problem. A good model to follow is the FIRST Lego-league project, where the students given a Lego Mindstorms kit and work in teams to solve an engineering design challenge.

In Phase IV the students take six credit hours of college level classes. These classes include a technical math class, an engineering graphics class, and an engineering design class. One the main challenges with these students was the varying mathematics capability the students had. We found that while for some students the math class was merely a review, for other students it was quite challenging. We have yet to decide how to resolve this issue.

A separate closing session was held at each school, on the last day. The Phase IV students were invited to the VCU final session. Parents were invited, and a speaker, Ms. Naomi Weathers, was present at the VCU closing session. All students received certificates of completion. In addition, several students $(\sim 25)$ received special certificates for outstanding achievement. The Phase I students received certificates and prizes from VDOT during the bridge building and testing section.

IV. Conclusion 
In a world where education is the key to success, it is important to impress upon our young people that they must reach into their communities and build bridges that will allow them to passage into a world full of opportunities and possibilities. Participating in RAPME is a way of accomplishing this.

The new millennium is here. As we leave the information age and enter the age of technology, engineering will definitely be a part of it. Engineering will be the career of the new millennium and we need to give our students-who are the future - the proper tools with which to survive. RAPME is one such tool.

ROSALYN S. HOBSON

Rosalyn Hobson is an Assistant Professor of Electrical Engineering at Virginia Commonwealth University.

KENNETH BURBANK

Kenneth Burbank is a professor in the Engineering Technology Department at Virginia State University. 